\title{
Occurrence of Intestinal Parasitosis among Schoolchildren in Lago Azul, municipality of Novo Gama, Goiás, Brazil
}

\author{
Folha JS'2 Vilhena V' ${ }^{2}$, Rocha CRR ${ }^{1}$, Sá LCEF ${ }^{1}$, Reis LJB ${ }^{1,2}$, Eduardo ALMN ${ }^{2,3}$, Affonso RS $^{3,4}$ and Machado \\ $\mathrm{ER}^{* 1,2,3,4}$ \\ ${ }^{1}$ Department of Biology, Brazil \\ ${ }^{2}$ Department of Biomedicine, Brazil
}

${ }^{3}$ Department of Pharmacy, Brazil

${ }^{4}$ Department of Nurseries, Brazil

*Corresponding author: Eleuza Rodrigues Machado, Anhanguera Faculty of Brasília, Taguatinga Unit, Brazil

\begin{tabular}{|c|c|}
\hline ARTICLE INFO & ABSTRACT \\
\hline & Intestinal parasites are a worldwide public health problem that affects all age groups \\
\hline Published: 櫘 April 04, 2019 & being more frequent in children. In this study we assessed the occurrence of intestinal \\
\hline $\begin{array}{l}\text { Citation: Folha JS, Nascimento VV, Ro- } \\
\text { cha CRR, Sá LCEF, Reis LJB, Eduardo } \\
\text { ALMN, Affonso RS, Machado ER. Occur- } \\
\text { rence of Intestinal Parasitosis among } \\
\text { Schoolchildren in Lago Azul, municipal- } \\
\text { ity of Novo Gama, Goiás, Brazil. Biomed } \\
\text { J Sci \& Tech Res 16(5)-2019. BJSTR. } \\
\text { MS.ID.002905. }\end{array}$ & $\begin{array}{l}\text { marães, Novo Gama Township, GO, Brazil, and attempted to establish associated risk } \\
\text { factors. Fecal samples collected from } 60 \text { schoolchildren were analysed employing the } \\
\text { Hoffman-Pons-Janer and Ritchie parasitological methods. Enteroparasites or commensal } \\
\text { species were detected in } 33 \text { samples revealing an overall prevalence rate of } 55 \% \text {. Giardia } \\
\text { lamblia was present in } 42 \% \text { of the school children, while Entamoeba coli was identified in } \\
69 \% \text {, Endolimax nana in } 9 \% \text {, Enterobius vermicularis in } 6 \% \text {, Strongyloides stercoralis and } \\
\text { Entamoeba histolytica/dispar in } 3 \% \text {, each. In view of these results, educational measures } \\
\text { for the students, parents and teachers were taken, as well as referral of positive children } \\
\text { for free treatment. }\end{array}$ \\
\hline
\end{tabular}

Keywords: Enteroparasites; Commensal; Schoolchildren; Novo Gama; Goiás

\section{Introduction}

Enteroparasitic protozoans and helminths are an important worldwide public health problem. They are endemic in various regions of the globe, and more frequent in developing countries. The problem affects all age groups, with higher prevalence among children. These infections may cause gastrointestinal disorders and, in cases of high burden, even detain physical and cognitive child development $[1,2]$. In tropical and subtropical regions, like Brazil, environmental factors such as high annual average temperatures combined with a lack of structure in sanitation in poor areas provide ideal conditions for the full development of the life cycle of many species of enteroparasites [3,4]. Giardia lamblia is the most common intestinal protozoa in in Brazil, and helminths like Ascaris lumbricoides and Trichuris trichiura are frequently present in low-income communities $[5,6]$. Yet, other parasitic diseases such as amebiasis, schistosomiasis, hymenolepiasis, taeniasis, ancylostomiasis, enterobiasis and strongyloidiasis contribute to aggravate the epidemiology of Neglected Tropical Diseases (NTDs) in the country [7, 8, 9, 10].

Human intestinal parasite infections generally occur by the fecal-oral route, with the ingestion of cysts, oocysts, eggs or larvae present in contaminated food or water, or via active larvae penetration through the skin or mucous membranes [11, 12]. Inadequate sanitation, low socio-economic and cultural levels, lack of health guidance and poor hygiene are directly related to the intensity of infections and spread of enteroparasites.

Though preventable and treatable, these NTDs often represent a burden to public health and the economy of low and middle-income countries (LMIC). Poverty, under diagnosis, lack of treatment, nutritional and immune deficiencies are associated with the 
occurrence of chronic debilitating conditions that could be avoided with relatively simple public health measures [13].

Acute or chronic diarrhea, constipation, abdominal cramps, epigastric pain, appetite loss or perversion, and anemia are the most common symptoms of intestinal parasitosis [14,15]. Clinical manifestations of enteroparasitic infections depend directly on the pathogenicity of the parasite, the host immune response, and the parasite load [16]. Among schoolchildren, parasitic infections sign to a lack of effective sanitation and educational policies, evidencing the necessity of public information about the habits and conditions contributing to the transmission of NTDs [17]. School-aged children are often the main targets for parasites due to the constant exposure to reinfection conditions [18].

The aim of this study was to evaluate the occurrence of enteroparasites among 4-9 year old school children from the borough of Lago Azul, municipality of Novo Gama, Goiás, Brazil, in an attempt to contribute for the assessment of the epidemiological profile in the area, and for the implementation, by competent organs, of control and prevention measurements for promoting heath and a better life quality.

\section{Material and Methods}

The study was conducted between August and September of 2014 on the 'Ulysses Guimarães Municipal School' located at Lago Azul, municipality of Novo Gama, GO, Brazil. Created in 1974 and initially designed 'Park Estrela Dalva VI', the borough has nowadays an estimated population of 104,889 inhabitants [20]. Some areas are deficient in public services like water supply and sewage network and some locals are used to drinking tap water, although it cannot be considered safe and clean. People still use artesian wells and septic tanks to overcome the problem of lack of treated water and sanitation. The sample size $(\mathrm{n}=60)$ was calculated using, as a parameter, the study of Gonçalves and co-workers [21]. Sixty children of both genders, aging four to nine years and regularly attending four different classes of the elementary school in the municipality of Novo Gama, GO, Brazil, were enrolled. Children's parents or guardians signed a free and informed consent form, according to the resolution 196/96 of the National Health Council. The survey was approved by the Ethics Committee on Human Research of the Health Secretariat of the Federal District.

The requested fecal samples were collected by parents or guardians, after guidance on the procedures in a presentation at the school. Each participant received two appropriate containers. The recipients were identified with the student's name and date of collection. At the time of the lecture, a socio-economic questionnaire including questions about the domestic habits of the children was applied to the parents/guardians. Properly identified samples received in a $4-5$ days interval, were $10 \%$ formalin-fixed (1:2) and packed with ice in Styrofoam boxes for transportation. The samples were transported at the same day to the Medical Parasitology and Vector Biology Laboratory at the Faculty of Medicine in the
Federal University of Brasília (UnB), where they were processed and analysed. Two methods of analysis were employed: the spontaneous sedimentation procedure and the Ritchie centrifugalsedimentation method, both useful for detection of protozoan cysts, oocysts and helminthic eggs or larvae, routinely employed and widely described in the literature $[22,23]$.

Sixslides of each sample were prepared: three for the spontaneous sedimentation procedure, and three for the centrifugation method. Each sample was analysed by two investigators (researcher/ collaborator) totalling 720 slides observed. Biosecurity standards were strictly followed in the diagnosis and slides preparation $[22,23]$. Enteroparasites and commensal species were identified according to the morphology and size of specimens as described in the literature [23]. Statistical analyses were performed by the Fisher method and Chi-square test (c2), using the GraphPad InStat 3. The results were significant when $p \leq 0.05$. Once concluded the samples analysis, positive children's parents/guardians were referred to a medical facility at the Lago Azul municipality (Novo Gama, GO, Brazil), with an indication by the researcher, to be provided with free medication for the diagnosed parasitic diseases.

\section{Results}

Of the 60 stool samples examined, 35 (58.3\%) were from female and $25(41.7 \%)$ from male children. Overall, 33 (55.0\%) samples tested positive for intestinal parasites/commensal species with $33.3 \%$ positivity among girls and $21.7 \%$ among boys showing no statistical difference between genders, with $\mathrm{p}>0.05$ (Table 1). Among the positive cases, $8(24.2 \%)$ were infected by only one parasite, while biparasitism was detected in 2 samples (6.1\%). Regarding commensals, 10 out of 33 samples had one commensal species (33.3\%), nine (27.3\%) had one parasite/one commensal and in four cases $(12.1 \%)$ two different parasites and one commensal were detected (Figure 1). Concerning the age, it has to be considered that there was a higher number of samples from children aged 4-6 year (41 samples), hence concentrating higher rates of positivity in this band. Thus, $60.6 \%$ of positive specimens (20/33) were from four to six old children, but, considering the absolute number of samples analysed in three tracks: four to six years; six to eight years and over eight years, there was no statistically significant difference in the age distribution (Table 2).

Table 1: Distribution by gender and frequency of intestinal parasites among schoolchildren from Novo Gama, GO, Brazil, in August and September 2014.

\begin{tabular}{|c|c|c|c|c|c|}
\hline \multirow{2}{*}{ Stool Examination } & \multicolumn{2}{|c|}{ Female } & \multicolumn{2}{c|}{ Male } & \multirow{2}{*}{ Total } \\
\cline { 2 - 5 } Positive & $\mathbf{N}$ & $\mathbf{\%}$ & $\mathbf{N}$ & $\mathbf{\%}$ & \\
\hline Negative & 15 & 33.3 & 13 & 21.7 & 33 \\
\hline Total & 35 & 58.3 & 25 & 41.7 & 60 \\
\hline
\end{tabular}


Table 2: Parasitic and commensal species frequency and distribution by age and gender in schoolchildren from Novo Gama, GO, Brazil, in August and September 2014.

\begin{tabular}{|c|c|c|c|}
\hline Age (years) & Positive & Negative & Total \\
\hline $4+6$ & 20.0 & 21.0 & 41.0 \\
\hline $6+8$ & 8.0 & 4.0 & 12.0 \\
\hline $8>$ & 5.0 & 2.0 & 7.0 \\
\hline Total & 33.0 & 27.0 & 60.0 \\
\hline
\end{tabular}

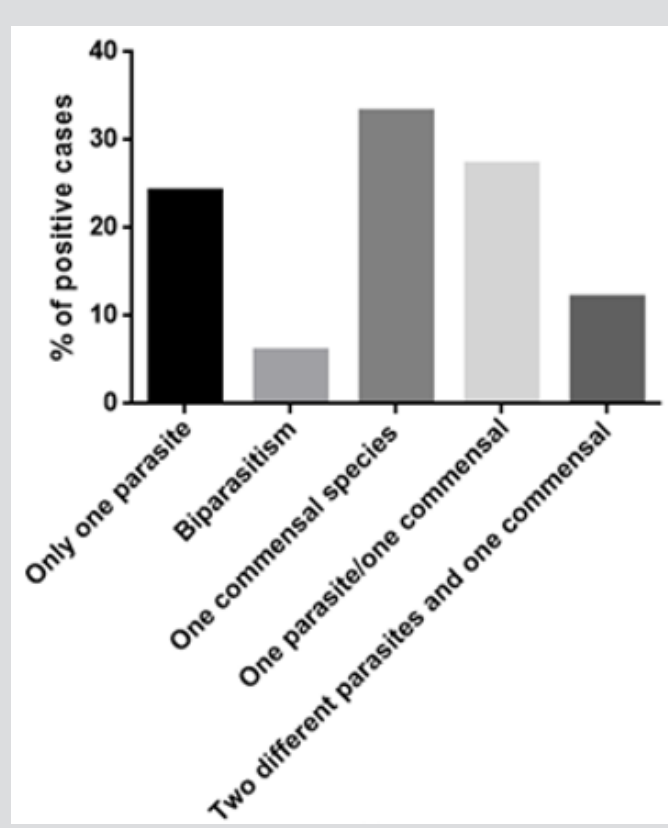

Figure 1: Frequency de monoparasitism, biparasistism, and poliparasitism by enteroparasites and commensal species detected by stool examination of children from a public school in the municipality of Novo Gama, GO, Brazil, in August and September 2014.

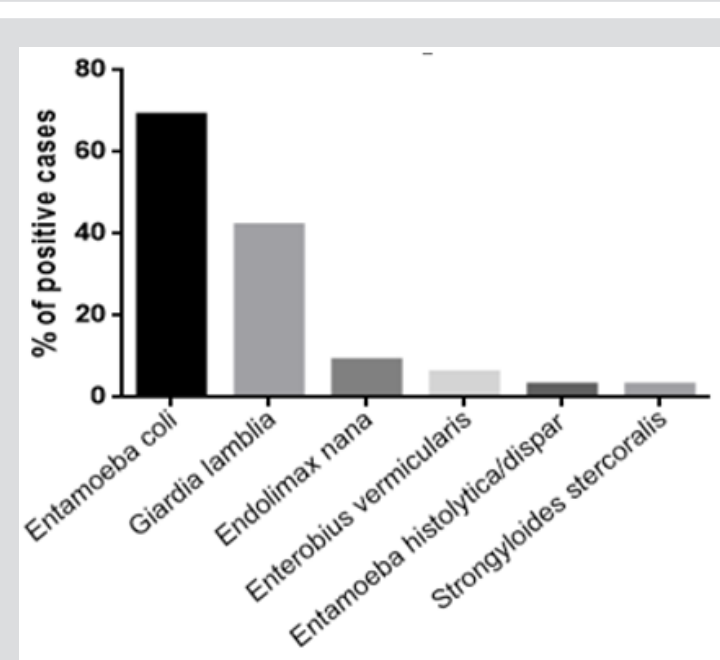

Enteroparasites and commensal species detected

Figure 2: Enteroparasites and commensal species detected by stool examination of children from a public school in the municipality of Novo Gama, GO, Brazil, in August and September 2014.
The employment of two parasitological methods for stool examination allowed detection of protozoan cysts and helminth eggs/larvae. Entamoeba coli cysts were observed in 23 (69\%) of the 33 positive samples; cysts of Giardia lamblia in 14/33 (42\%), Endolimax nana cysts in 3/33 (9\%), Entamoeba histolytica/dispar cysts in 1/33 (3\%), Enterobius vermicularis eggs in 2/33 (6\%), and infective larvae of Strongyloides stercoralis in 1/33 (3\%), as shown in Figure 2. All parents/guardians of the schoolchildren enrolled attended the request for filling a socioeconomic, domestic habits and symptoms report questionnaire aiming to detect possible associations between risk factors and the enteroparasitic infections. At least one of the eight questions were answered in $100 \%$ of the questionnaires applied. Reported symptoms include decreased appetite (36.7\%), and anal pruritus (18.5\%) among others detailed in Table 3. On evaluation of risk factors for the acquisition of enteroparasitic infections $36.7 \%$ of parents/guardians reported that children are often barefoot, against $63.3 \%$ who said they are used to wear shoes. Nail biting habits were reported by $31.7 \%$ of the questioned. Other risk factors assessed are depicted in Table 4. In relation to socioeconomic and environmental conditions, the origin of the domestic consumed water was ascertained. Twentytwo parents/guardians (36.7\%) reported tap water ingestion, 19 (31.6\%) informed clay filter use, nine reports (15\%) of water purifier usage, seven $(11.7 \%)$ of mineral water consumption and three $(5 \%)$ of artisan well taken water use.

Table 3: Symptoms indicative of enteroparasitic infection reported by parents/guardians of children from a public school in the municipality of Novo Gama GO, Brazil, in August and September 2014.

\begin{tabular}{|c|c|c|}
\hline Symptoms & Cases numbers & Percentage \\
\hline Diarrhea & 3.0 & 5.0 \\
\hline Anal pruritus & 11.0 & 18.5 \\
\hline Abdominal pain & 10.0 & 16.7 \\
\hline Insomnia & 7.0 & 11.7 \\
\hline Decreased appetite & 22.0 & 36.7 \\
\hline Skin patches & 9.0 & 15.0 \\
\hline Weakness & 3.0 & 5.0 \\
\hline Nausea and vomiting & 7.0 & 11.7 \\
\hline
\end{tabular}

Table 4: Questionnaire evaluation of cultural and infrastructural variables associated with the transmission of enteroparasitic and/or commensal species for schoolchildren of Novo Gama, GO, Brazil, in August and September 2014.

\begin{tabular}{|c|c|c|}
\hline $\begin{array}{c}\text { Risk Factors* / Personal Hygiene } \\
\text { habits }\end{array}$ & $\begin{array}{c}\text { Number of } \\
\text { cases }\end{array}$ & Percentage \\
\hline $\begin{array}{c}\text { Do not washing hands after going to the } \\
\text { toilet }\end{array}$ & 15.0 & $25.0^{*}$ \\
\hline Washing hands after going to toilet & 25.0 & 41.7 \\
\hline Do not washing hands before meals & 11.0 & $18.3^{*}$ \\
\hline Washing hands before meals & 25.0 & 41.7 \\
\hline Nailbiting & 19.0 & $31.7^{*}$ \\
\hline Walking barefoot & 22.0 & $36.7^{*}$ \\
\hline Washing food before eating them & 29.0 & 48.3 \\
\hline
\end{tabular}




\begin{tabular}{|c|c|c|}
\hline Do not washing food before eating them & 1.0 & 1.7 \\
\hline Drinking filtered water & 31.0 & 51.7 \\
\hline Do not drinking filtered water & 17.0 & $36.7^{*}$ \\
\hline
\end{tabular}

\section{Discussion}

This study evaluated the presence of intestinal parasites in 60 children from an urban community located in an area where public services are limited or deficient. In the target area, Lago Azul, municipality of Novo Gama, GO, Brazil, even when a water supply system is available, the use of porous porcelain filters for prevention of waterborne diseases is highly recommended households. Chlorination is often ineffective for the elimination of parasitic forms in concentrations tolerable for the human consumption [21]. Besides, in urbanities where the provision of public services is inadequate, there is a possibility of contamination of groundwater and artesian wells. According to the The WHOUNEP Health and Environment Linkages Initiative (HELI) [24], more than 50 infections are associated with human excreta and to guarantee a safe water supply, it is essential to keep the water sources free of any excreta contamination. Even when much effort is done to provide safe water for the population if technical norms are not strictly observed and local specificities such as sociocultural factors, soil type and settlement rates, are not respected, the investments can be worthless [24].

Many Lago Azul residents make their living as construction workers and most jobs are in the city of Brasilia, the Brazilian federal district. They also depend on federal resources of the country's capital for medical/hospital care and, in parallel, educational levels are generally low with a high percentage of uneducated people. Our data highlight the need for more resources and governmental initiatives to enhance the quality of public services offered to poor communities exposed to the risk of infectious and parasitic diseases.

As parasitic infections intensity is expected to vary based on the degree of exposure to risk factors, our questionnaire analysis of domestic habits (Table 4) subsidized the well-known correlation between the lack of some hygienic habits like washing hands before meals, nail gnaw custom, no shoes or drinking tap water where the public services are not satisfactory were shown to be present in infected children of the community.

In our survey, the use of two stool examination methods proved efficient for the detection of the distinct parasitic forms. As demonstrated by other authors, the use of techniques such as spontaneous sedimentation and sedimentation by centrifugation are easy to perform and inexpensive routine procedures that allow a complete "ova and parasite examination" for parasites [25,26]. The positivity rate of 55\% observed in 60 stool specimens analysed includes parasites and commensal species. Protozoan cysts were the most frequent parasitic forms detected, evidencing Entamoeba coli, G. lamblia, Endolimax nana and E. histolytica/dispar infections among the schoolchildren analysed, as frequently observed in surveys carried out in areas of equivalent socioeconomic pattern [27]. Eggs and larvae of the nematodes E. vermicularis and S. stercoralis were also seen, as well as A. lumbricoides, E. coli, (end point only. Eliminate: “, and G. lamblia). Similar surveys carried out in different regions of Brazil, have detected school children's enteroparistes prevalences that vary from one region to another [28]. Progress towards the control of parasitic infections depends largely on measures that, besides respecting the peculiarities of each region, are sustainable and offer feasible solutions for reducing the exposure to well known risk factors.

Regarding differences by gender, Machado et al [29] observed a 2.7 times higher risk to acquire intestinal parasites in male children than in females. In our survey no such significant differences were detected.

Concerning the occurence of commensal species that colonize the human intestines, we found a positivity rate of $78 \%$, being Entamoeba coli the most frequent organisms, present in $69 \%$ of the stool samples analysed. Endolimax nana cysts were observed in $9 \%$ of the examinated material. These species are considered non-pathogenic to the host, but it is important to describe them because they reflect the environmental problems of the target area [30]. The presence of such commensal species evidence water/soil contamination with fecal material from humans or other animals. Protozoan cysts in the water used in households have important implications for the epidemiology of parasitic diseases [31]. In places where fecal contamination of water is present, species of pathogenic parasites most likely are present [32,33].

E. vermicularis eggs were identified in $6 \%$ of the samples examined and $S$. stercoralis larvae had 3\% positivity. Based on other Brazilian studies that, using the methods of Graham, for the detection of E. vermicularis, and Baermann-Moraes for S. stercoralis larvae search, our results are within the expected. Others have found $5 \%$ positivity for E. vermicularis in the Amazonian region and $2.2 \%$ to $5.6 \%$ of samples positive for $S$. stercoralis in the state of Minas Gerais $[34,35]$. The transmission of enterobiasis is especially common in school children. Due to the easy dispersion of eggs, when infected people are around, the environment, clothing and utensils get contaminated and the infection disseminates. Nocturnal anal pruritus is the main clinical feature of enterobiasis [36,37]. While $6 \%$ of the samples were positive for E. vermicularis, anal pruritus was reported by $18.5 \%$ of parents/guardians who responded to the questionnaire. This data may indicate that the symptom can be related to other causes, including flaws in the children's personal hygiene. It's important to note that poor hygiene practices has impact in the prevalence of intestinal parasitic infections, once it assures the transmission of the parasite forms, especially in the school environment.

The risk factors for parasitic infections assessed by questions related to the children's hygiene practices revealed an alarming sit- 
uation in the community of Lago Azul, Novo Gama, GO. Poor household caring practices such as not washing hands after using the toilet or prior to eating, nail biting, not wearing shoes and drinking tap water were reported by a high percentage of the parents or guardians enrolled in this study. Our data confirm and highlight the crucial need for sanitary and health measures to contain the spread of intestinal parasites among schoolchildren in underprivileged communities of Brazil showing a correlation between some cultural and infrastructural variables with the prevalence of enteroparasitic infections [2, 34, 38]. The Lago Azul neighbourhoods, GO, has two health units available for its inhabitants but the service centres do not meet the demand, leading local people to seek for medical healthcare in the federal capital. The town does not have a broad wastewater treatment network and, as a result, part of the population still uses artesian wells.

These wells are, in many cases, built in disagreement with the technical safety standards causing the water to be contaminated with sewage. Besides, the habit of drinking tap water is a risk factor in the region, since flaws in the water supply networks are not uncommon [32]. Based on these factors, we believe that the inhabitants of that community are constantly exposed to parasitic infections that can pose great impact on the local public health. Intestinal parasites are common in school age children due to sanitary problems, inadequate educational and socioeconomic conditions. Thus, it is of fundamental importance the implementation of basic sanitation and guidance on hygiene and health education campaigns, which must be carried out mainly among children, in order to make progress and sediment the general population to good hygiene and health at the household and family environment, preventing diseases that affect the quality of life at the individual and collective level.

\section{Conclusion}

The occurrence of enteroparasites and commensal species were high among the examined schoolchildren. Therefore, the results point to a need to implement preventive and educational measures urgent among school goers' public school in Novo Gama, GO, Brazil. Our data can help to guide health infrastructure projects aiming to improve the quality of life and reduce the prevalence of intestinal parasites prevalent in the region. Conduct educational campaigns that promote behavioural changes could be valuable in controlling these infections among children and other inhabitants of Lago Azul.

\section{References}

1. Alemu G, Abossie A, Yohannes Z (2019) Current status of intestinal parasitic infections and associated factors among primary school children in Birbir Town, Southern Ethiopia. BMC Infect Dis 19(1): 270.

2. Fonseca REPD, Barbosa MCR, Ferreira BR (2017) High prevalence of enteroparasites in children from Ribeirão Preto, São Paulo, Brazil. Rev Bras Enferm 70(3): 566-571.

3. Machado ER, Matos NO, Rezende SM, Carlos D, Silva TC, et al. (2018) Host-parasite interactions in individuals with Type 1 and 2 diabetes result in higher frequency of Ascaris lumbricoides and Giardia lamblia in Type 2 Diabetic Individuals. J Diabetes Res 4238435.
4. Muñoz-Antoli C, Pavon A, Marcilla A, Toledo R, Esteban JG (2014) Prevalence and risk factors related to intestinal parasites among children in department of Rio San Juan, Nicaragua. Trans R Soc Trop Med Hyg 108(12): 774-782.

5. Barbosa CV, Barreto MM, Andrade RJ, Sodré F, d'Avila-Levy CM, et al. (2018) Intestinal Parasite Infections in a Rural Community of Rio de Janeiro (Brazil): Prevalence and Genetic Diversity of Blastocystis Subtypes. PLoS One 13(3): e0193860.

6. Andrade SS, Teodoro LM, Viana DJ, Canuto-Sales EM, Bahia-de-Oliveira $\mathrm{GH}$, et al. (2017) Intestinal parasites in public transport buses from the city of Diamantina, Minas Gerais, Brazil. Res Rep Trop Med 8: 59-63.

7. Costa JO, Resende JA, Gil FF, Santos JFG, Gomes MA (2018) Prevalence of Entamoeba histolytica and other enteral parasitic diseases in the metropolitan region of Belo Horizonte, Brazil. A cross-sectional study São Paulo Med J 136(4): 319-323.

8. Sousa SRM, Carvalho AQ, Cardoso JFN, Coelho PMZ, Geiger SM, et al. (2017) Schistosomiasis in the Amazon region: is the current diagnostic strategy still appropriate? Rev Soc Bras Med Trop 50(6): 848-852.

9. Monteiro KJL, Reis ERCD, Nunes BC, Jaeger LH, Calegar DA, et al. (2018) Focal persistence of soil-transmitted helminthiases in impoverished areas in the State of Piaui, Northeastern Brazil. Rev Inst Med Trop São Paulo 60: e24.

10. Valença Barbosa C, de Jesus Batista R, Pereira Igreja R, d'Avila Levy CM, Werneck de Macedo H, et al. (2017) Distribution of Blastocystis subtypes isolated from humans from an urban community in Rio de Janeiro, Brazil. Parasit Vectors 10(1): 518.

11. Mendonça Ambrozim F, Pezzin J, Barreto Teresa Gradella D, Andrade de Souza MA (2017) Enteroparasites in vegetables marketed in an ancient Brazilian city. Rev Salud Publica (Bogotá) 19(5): 635-640.

12. Bahmani P, Maleki A, Sadeghi S, Shahmoradi B, Ghahremani E (2017) Prevalence of Intestinal Protozoa Infections and Associated Risk Factors among School children in Sanandaj City, Iran. Iran J Parasitol 12(1): 108116.

13. World Health Organization. Accelerating work to overcome the global impact of neglected tropical diseases. A roadmap for implementation . Geneva: World Health Organization; 2012.

14. Hussein EM, Zaki WM, Ahmed SA, Almatary AM, Nemr NI, et al. (2016) Predominance of Giardia lamblia assemblage A among iron deficiency anaemic pre-school Egyptian children. Parasitol Res 115(4): 1537-1545.

15. Baghlaninezhad R, Beiromvand M, Veisi MS (2019) Analysis of knowledge and attitudes related to parasitic infections among inhabitants of Ahvaz County, Khuzestan Province, Iran. Acta Trop 193: 211-216.

16. Saldiva SR, Carvalho HB, Castilho VP, Struchiner CJ, Massad E (2002) Malnutrition and susceptibility to enteroparasites: reinfection rates after mass chemotherapy. Paediatr Perinat Epidemiol 16(2): 166-171.

17. Muñoz Antoli C, Gozalbo M, Pavón A, Pérez P, Toledo R, et al. (2018). Enteroparasites in Preschool Children on the Pacific Region of Nicarágua. Am J Trop Med Hyg 98(2): 570-575.

18. Bastos VK, Cutolo SA, Doria M do C, Razzolini MT (2013) Detection and quantification of viable Ascaris $s p$. and other helminth eggs in sewage sludge. Int J Environ Health Res 23(4): 352-362.

19. Muñoz Antoli C, Pavón A, Marcilla A, Toledo R, Esteban JG (2014) Prevalence and risk factors related to intestinal parasites among children in Department of Rio San Juan, Nicarágua. Trans R Soc Trop Med Hyg 108(12): 774-782.

20. (2014) Instituto Brasileiro de Geografia e Estatística (IBGE). Net. Disponível em: Acesso em: 10 de out. de 2014.

21. Gonçalves AL, Belizário TL, Pimentel JB, Penatti MP, Pedroso R dos S (2011) Prevalence of intestinal parasites in preschool children in the region of Uberlândia, State of Minas Gerais, Brazil. Rev Soc Bras Med Trop 44 (2): 191-193. 
22. Machado ER, Costa Cruz JM (1998) Strongyloides stercoralis and other enteroparasites in children at Uberlândia city, state of Minas Gerais, Brazil. Mem Inst Oswaldo Cruz 93(2): 161-164.

23. De Carlli GA (2011) Clinical Parasitology: selection of methods and laboratory techniques for the diagnosis of human parasitosis. $2^{\text {a }}$ Ed- São Paulo, Atheneu.

24. Novaković B, Kristoforović Ilić M, Trajković Pavlović L, Torović L, Jevtić M, et al. (2007) Health and environment. Med Pregl 60(11-12): 569-574.

25. de Carvalho TB, de Carvalho LR, Mascarini LM (2006) Occurrence of enteroparasites in day care centers in Botucatu (São Paulo State, Brazil) with emphasis on Cryptosporidium sp., Giardia duodenalis and Enterobius vermicularis. Rev Inst Med Trop Sao Paulo 48(5): 269-273.

26. Toledo MJ, Paludetto AW, Moura F de T, Nascimento ES, Chaves M, et al. (2009) Evaluation of enteroparasite control activities in a Kaingáng community of Southern Brazil. Rev Saude Publica. 43(6): 981-990.

27. Kim MJ, Jung BK, Cho J, Kim DG, Song H, et al. (2016) Prevalence of Intestinal Protozoans among School children in Suburban Areas near Yangon, Myanmar. Korean J Parasitol 54(3): 345-348.

28. Ferreira UM, Ferreira CS, Monteiro CA (2000) Secular trend of intestinal parasitic diseases in childhood in the city of São Paulo (1984-1996). Revista Saúde Pública 34: 73-82.

29. Machado ER, Santos DS, Costa Cruz JM (2008) Enteroparasites and commensals among children in four peripheral districts of Uberlândia, State of Minas Gerais. Rev Soc Bras Med Trop 41(6): 581-585.

30. Matsumura T, Hendarto J, Mizuno T, Syafruddin D, Yoshikawa H, et al. (2019) Possible pathogenicity of commensal Entamoeba hartmann revealed by molecular screening of healthy school children in Indonésia. Trop Med Health 47: 7

ISSN: 2574-1241

DOI: 10.26717/BJSTR.2019.16.002905

Eleuza Rodrigues Machado. Biomed J Sci \& Tech Res

This work is licensed under Creative Commons Attribution 4.0 License

Submission Link: https://biomedres.us/submit-manuscript.php
31. Macedo HS (2005) Prevalence of intestinal parasites and commensals in children of municipal public schools in Paracatu (MG). Rev Bras de Análises Clínicas 37(4): 209-213.

32. da Silva JB, Piva C, Falavigna-Guilherme AL, Rossoni DF, de Ornelas Toledo MJ (2016) Spatial distribution and enteroparasite contamination in peridomiciliar soil and water in the Apucaraninha Indigenous Land, southern Brazil. Environ Monit Assess 188(4): 217.

33. Feng M, Pandey K, Yanagi T, Wang T, Putaporntip C, et al. (2018) Prevalence and genotypic diversity of Entamoeba species in inhabitants in Kathmandu, Nepal. Parasitol Res 117(8): 2467-2472.

34. Valverde JG, Gomes-Silva A, De Carvalho Moreira CJ, Leles De Souza D, Jaeger LH, et al. (2011) Prevalence and epidemiology of intestinal parasitism, as revealed by three distinct techniques in an endemic area in the Brazilian Amazon. Ann Trop Med Parasitol 105(6): 413-424.

35. Melo MCB, Klem VGQ, Mota JAC, Penna FJ (2004) Intestinal Parasitosis intestinais. Rev Med Minas Gerais. Minas Gerais 14: 3-12.

36. Faria CP, Zanini GM, Dias GS, da Silva S, de Freitas MB, et al. (2017) Geospatial distribution of intestinal parasitic infections in Rio de Janeiro (Brazil) and its association with social determinants. PLoS Negl Trop Dis.11(3): e0005445.

37. Sammour ZM, Gomes CM, Tome AL, Bruschini H, Srougi M (2008) Prolonged irritative voiding symptoms due to Enterobius vermicularis bladder infestation in an adult patient. Braz J Infect Dis 12(4): 352.

38. Giraldi N, Vidotto O, Navarro IT, Garcia JL (2001) Enteroparasites prevalence among daycare and elementary school children of municipal schools, Rolândia, PR, Brazil. Rev Soc Bras Med Trop. 34(4): 385-387.

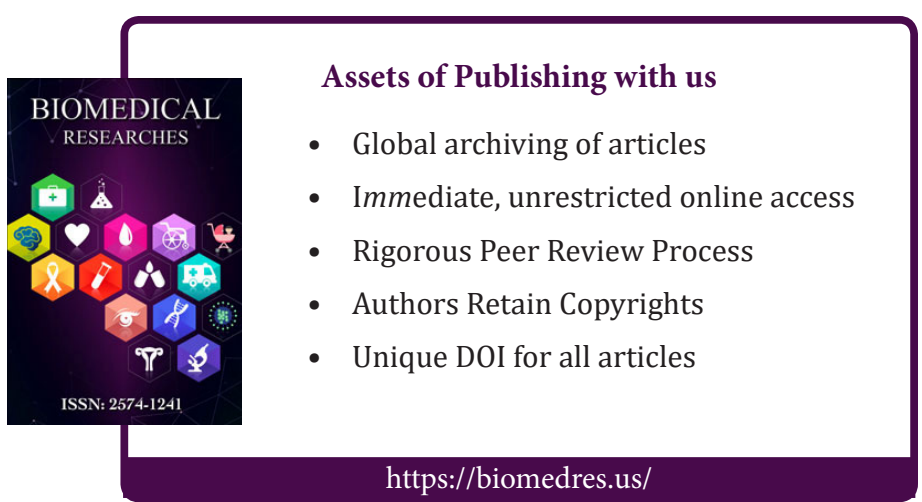

